\section{Commentary: Cor triatriatum dexter: Persistent tissue causing protean issues!}

\author{
T. K. Susheel Kumar, MD
}

Cor triatriatum dexter is a rare congenital cardiac anomaly caused by the abnormal persistence of embryonic tissue guarding the primitive sinoatrial orifice. ${ }^{1,2}$ The pathophysiology is determined by a number of factors that come into interplay, including the size of the sinoatrial orifice, the presence of atrial communication, and the degree of tricuspid valve obstruction. The manifestations are indeed variable, with clinical presentation ranging from abdominal distension and cyanosis to incidental findings during correction of other cardiac malformations. ${ }^{3,4}$ The chronicity of this lesion only adds to its protean character as illustrated in this case report. ${ }^{5}$

Tricuspid regurgitation is an unusual manifestation of cor triatriatum dexter and probably related to repetitive trauma and consequent deformation of the tricuspid valve leaflets from the bulging membrane. Although the authors have done a commendable job of collating the various case reports on this rare congenital heart defect from literature, the disease is under-reported and not as exotic as this study suggests. ${ }^{5}$ Most cases are asymptomatic and others coexist as part of other complex congenital heart defects. The study also raises an important question regarding the risks of conservative management in a largely asymptomatic child with well-documented membrane in the right atrium. The risks to the tricuspid valve tissue should not be ignored and the surgical correction of the defect can become complicated.

\footnotetext{
From the Division of Congenital Cardiothoracic Surgery, Hassenfeld Children's Hospital at NYU Langone Health, New York, NY.

Disclosures: The author reported no conflicts of interest.

The Journal policy requires editors and reviewers to disclose conflicts of interest and to decline handling or reviewing manuscripts for which they may have a conflict of interest. The editors and reviewers of this article have no conflicts of interest.

Received for publication Aug 24, 2020; revisions received Aug 24, 2020; accepted for publication Aug 28, 2020; available ahead of print Sept 15, 2020.

Address for reprints: T. K. Susheel Kumar, MD, Department of Congenital Cardiothoracic Surgery, NYU Langone Health, New York, NY 10016 (E-mail: tksusheel. kumar@nyulangone.org).

JTCVS Techniques 2020;4:261

2666-2507

Copyright (C) 2020 The Authors. Published by Elsevier Inc. on behalf of The American Association for Thoracic Surgery. This is an open access article under the CC BY-NCND license (http://creativecommons.org/licenses/by-nc-nd/4.0/).

https://doi.org/10.1016/j.xjtc.2020.08.076
}

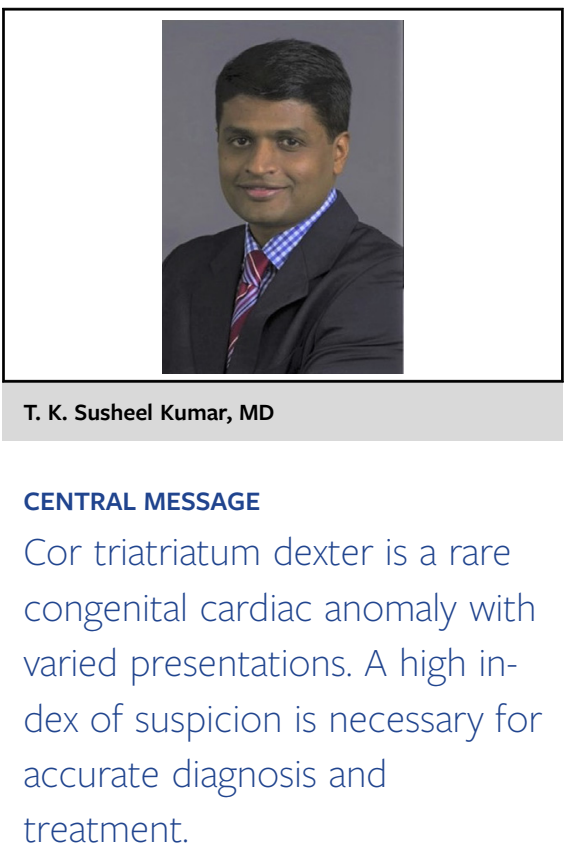

The challenge in management of this rare disorder is primarily related to its diagnosis, as the correction itself is usually straightforward. In addition to maintaining a high index of suspicion, the usage of a second modality of imaging such as cardiac magnetic resonance imaging can go a long way in making an accurate diagnosis.

\section{References}

1. Doucette J, Knoblich R. Persistent right valve of the sinus venosus. So-called cor triatriatum dexter: review of the literature and report of a case. Arch Pathol. 1963; 75:105-12.

2. Nakano S, Kawashima Y, Miyamoto T, Kitamura S, Manabe H. Supravalvular tricuspid stenosis resulting from persistent right sinus venosus valve. Ann Thorac Surg. 1974;17:591-5.

3. Alkhulaifi AM, Serraf A, Planche C. Ascites and weight loss in a child: due to congenital division of the right atrium. Cardiol Young. 1999;9:335-7.

4. Barrea C, Rubay J, Wagner K, Ovaert C. Cor triatriatum dexter mimicking Ebstein disease. Circulation. 2009;120:e86-8.

5. Kalangos A, Shatelen N, Demyanchuk V, Ruban N, Sfyridis P, Todurov B, et al Cor triatriatum dexter in children: literature review and case report. J Thorac Cardiovasc Surg Tech. 2020;4:254-8.

6. Rao S, Suntharos P, Najm H, Komarlu R. Cor triatriatum dexter with right ventricular hypoplasia: role of multimodality imaging in decision making. Echocardiography. 2018;35:2113-6. 